\title{
Toulmin Model: A Strategy for Critical Thinking in Analytical Reading
}

\author{
Maria Niayu Risma Novianti*
}

Sampoerna University, Indonesia

*Corresponding author. Email: maria.novianti@sampoernauniversity.ac.id

\begin{abstract}
Critical thinking skill is an important skill needed at the college or university level to read and write critically. The skill enhances students to analyze and evaluate the information as a response to the text. This research aims to reveal their abilities to read critically by using Kurland theory of critical reading level and Toulmin reasoning elements as the indicator for their performances. Content analysis was applied as a method to interpret response essays from 16 students of Academic Year 2019/2020 as the research samples. The result of this research showed that 31.25\% of students were still on the level of summary. $25 \%$ of students were on the level of descriptive and the percentage showed the same number for interpretation. $18.75 \%$ was the least percentage for the evaluation level. Thus, only 11 students made the claim successfully towards the author's purposes. Less than 10 students used the elements of warrant and rebuttal. The result concludes that the higher level of analytical skill is still below the majority. Therefore, some intensive reading programs or assessments need to be recommended as the possible solution for this research.
\end{abstract}

Keywords: Toulmin model, Critical thinking, Analytical reading.

\section{INTRODUCTION}

Critical thinking skill has commonly widespread among educational institutions. This skill highlights the importance of evaluation to absorb and identify information with "awareness, creativity, and refinement" [1]. It means students need to combine this skill with other cognitive aspects that enhance and sharpen their analytical and evaluation ability while reading the text or any information. However, implementing critical thinking skill in course materials and practices may not be simple. Nold finds that not all faculty members have enough understanding to increase students' ability in critical thinking [2]. Another report also stated that many instructors had not been well prepared or trained to teach this skill although they are determined to implement critical thinking into their courses [1]. Those difficulties experienced by some instructors may hinder one of the higher education goals to produce proficient graduates who are accommodated with critical thinking skill. Therefore, there should be an improvement in terms of strategies and techniques to develop this ability in the learning activities [2].

One of the strategies is developing assessments that are intended to explore students' ability to think critically into a higher level [3]. Those assessments could be found in analytical reading in which students are trained to be critical readers by examining the data and argument presented in the text [4]. As a result, students can practice and enhance their ability to be critical writers and readers at the same time in one particular assessment.

According to Kurland, reading process has three steps which are restatement, description, and interpretation [5]. In the process of restatement, readers are writing the summary by finding the main idea and major details. Then, the next step would be identifying the text components by looking at some aspects such as the author's point of view, evidence, and examples used by the author. The last step is interpreting or analyzing all those components which are connected each other to find the implicit meaning or motive hidden in the text.

Those processes of analytical reading proposed by Kurland may require a framework to identify the structure of the text, to interpret, and also to evaluate. Therefore, Toulmin model can be the framework or a method that can be aligned with the critical reading steps. Bermani et al. stated the model provides claim, data, warrant, backing, rebuttal, and qualifier. Each 
argument is supported by data that creates logical analysis as a warrant [6]. In other words, a warrant is the inference between the data and claim. Backing itself has a role that supports warrant by providing prior knowledge or evidence needed to support the inference [7]. If there is a rejection on the warrant; thus, rebuttal takes the position to deny the data and backing provided in the argument.

The relationship between the argument and warrant may be similar to the process of critical reading where the readers can examine the author's argument and warrant presented in the text. This model is not only rigidly used in writing an argument, but it can apply in other aspects of the text [8]. They could place themselves as challengers to reject or to accept the author's argument by looking at the warrant. The focus of the warrant can be the main area to test whether the author already provides a reasonable argument through his/her analysis supported by other backing [8]. Therefore, readers could provide more backing to the author's warrant when the logical analysis is accepted. Otherwise, the rebuttal is stated to reject the logical analysis provided by the authors. The figure 1 describes how Toulmin model can be assessed in critical reading, especially in the process of description, interpretation, and evaluation.

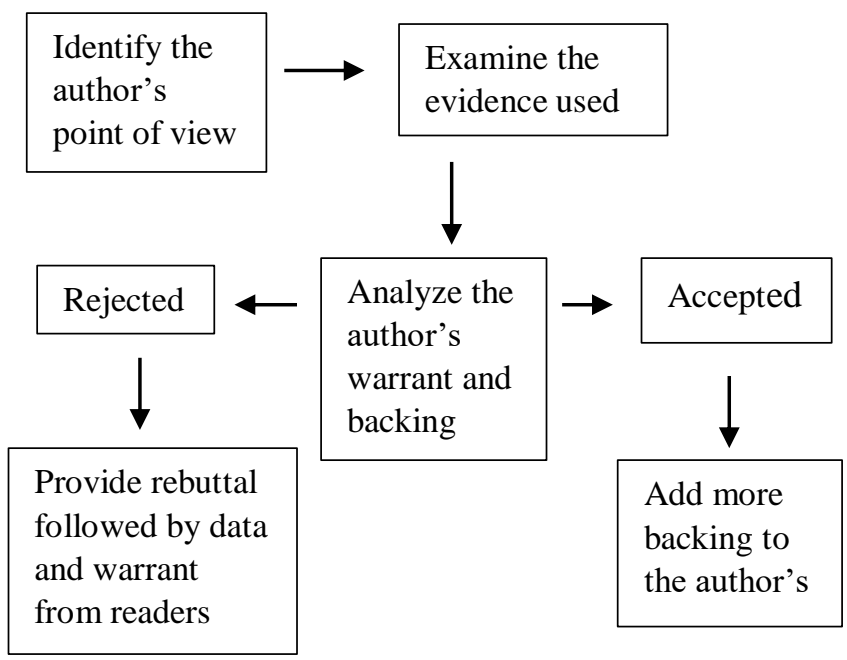

Figure 1 Toulmin Model in Critical Reading Framework

The figure 1 shows that the model for Kurland's critical reading starting from the description by using claim and data element to identify and analyse the component of the text. The students can point out the author's purpose or point of view through their claim and provide the data from the author's argument and evidence used. Tengberg and Scheller state three main criteria similar to Kurland's theory which are identifying, analysing, and evaluating. These criteria provide a space for readers to respond to the argumentative text [9]. The response creates a dialogical argumentation between the readers and the text which is also referring to Bakhtin's Dialogism as a 'conversation' among the authors [10]. Thus, the notion of Toulmin in critical reading is producing a response as a part of readers' interpretation and evaluation. Freeman highlighted that Toulmin model should be used as a dialogical argument between proponent and challenger to analyze the content of the argument [11]. The role of the challenger is needed to build a reasoned argument that can convince the challenger to accept the argument and warrant [4].

Therefore, applying this model in a critical reading and writing would enhance students' ability to examine and evaluate the argument. The Toulmin model can be an alternative to increase the students critical thinking in depth evaluation, since this model involves the high level of reasoning skills [8]. The use of a warrant can be one of the techniques to evaluate the argument by looking at the logical relationship. The Toulmin theory is also recommended to analyze the written and spoken argument to measure the validity and the reasons behind [6].

Some studies had been done to assess the implementation of Toulmin model in different contexts. Simosi investigated that the social context played an important role in understanding the oral argument using Toulmin model [12]. The study done by Jin Qin found that few students used counterargument or rebuttal to write argumentative papers after having reading activities as the references for the backing and also rebuttal [13]. Another research by Oliveras et. al. stated that the elements of Toulmin's model which are claim and data can be used as a technique in critical reading [14]. Leong also suggested that the logical relationship in Toulmin model allows the students to have deep critical thinking in criticizing the text [8]. Bermani et al. also states that Toulmin' theory is recommended to investigate the arguments' pattern through the elements of claim, data, warrant, backing, qualifiers, and refutation [6]. The currents studies have shown how this model is used as the framework of the students' ability to create the reasoned argument in argumentative writing although this model can also be applicable for writing response essays as critical reading assessments. However, the use of Toulmin model as the framework or pattern of analytical reading needs to research.

Therefore, this research would address a specific issue on how this model can be used as a framework for evaluating or criticizing the author's argument in the text through the reading process in a writing class. The writing assessment will focus on the rhetorical analysis where students have to criticize the author's opinion from online newspapers. Thus, two important aspects to examine are the level of critical reading the students acquired and the reasoning elements the students have applied. 


\section{METHODOLOGY}

\subsection{Design and Procedures}

Content analysis is used as the method of the research, especially to analyse the main instrument. Content analysis is a part of qualitative method that is intended to interpret the meaning of the data [15]. The data to analyze is in the form of verbal, visual, or written to 'create valid inference' objectively [16]. Thus, the students' essays will be the main objects of this research by taking the samples based on the grade categories. Based on the class activities, students had freedom to choose the provided newspapers based on their interests. Some response essays from each newspaper were taken randomly based on three grades: A, B, C to represent the high, middle, and low performance. Prior to this assignment, students were practicing responding to the argument and introduced to the logical fallacies which is one of the techniques to evaluate the argument. An outline was provided as the guideline to write the response essays.

\subsection{Participants}

The participants of this research were 29 undergraduate students joining Composition II in the odd semester of academic year 2019/2020. The students came from different faculties and cohorts since the class is offered as the compulsory subject across the faculties. The research used a purposive sampling by selecting 16 students' essays that had marks A, B, and C in each selected newspaper.

\subsection{Data Collection and Analysis}

Documentation is used as the main instrument of this research by using sixteen essays from the sampling student to be identified. The identification will follow the four stages of content analysis which are decontextualization, recontextualization, categorization, and compilation [16]. Decontextualization is the process where the units in the text is identified. Then, the process of identification is recontextualized again by reselecting the unit and removing the unnecessary units. Therefore, the chosen unit can be categorized based on the certain codes and theme to be analyzed in the process of compilation. As the result the coding process, the students' writing will be grouped into four levels of critical reading which are summary, description, interpretation, and evaluation. Then, the reasoning elements were identified starting from the description level where they started to identify the author's point of view and evidence.

\section{FINDINGS AND DISCUSSION}

\subsection{Students' Level on Critical Reading}

Based on table 1, it was found that several students were still in the level of summary although most of them had been able to identify the text in the descriptive level through the claim made. However, when the samples were categorized based on each level of reading comprehension, the summary level has the highest percentage, and the evaluation level has the least percentage as illustrated by the table below. Two other levels which are descriptive and interpretation have an equal percentage.

Table 1. Critical Reading Level

\begin{tabular}{|l|l|l|}
\hline Levels & $\begin{array}{l}\text { Number of } \\
\text { students }\end{array}$ & $\begin{array}{l}\text { Percentage } \\
(\boldsymbol{\%})\end{array}$ \\
\hline Summary & 5 & 31.25 \\
\hline Descriptive & 4 & 25 \\
\hline Interpretation & 4 & 25 \\
\hline Evaluation & 3 & 18.75 \\
\hline Total Number & $\mathbf{1 6}$ & $\mathbf{1 0 0}$ \\
\hline
\end{tabular}

The table 1 shows how several students still focused on the summary style to criticize the article by rewriting or restating the author's opinion as the main analysis although the total number was less than a half. However, the data shows that several students were still struggling to identify the text structure and interpret the meaning or the purpose of the author's argument. Excerpt 1 below shows how a student of summary level wrote his analysis by rephrasing the author's argument without giving further analysis to criticize "Free Speech is Killing Us" written by Andrew Marrantz.

\section{Excerpt 1 (Student A)}

Summary: Marantz provides cases such as internet that fueled campaign of Narendra Modi and Rodrigo Duterte and Donald Trump. He also stated some controversial cases like murder of heather heyer in Charlottesville Va and Walmart in majority-Hispanic part of El Paso. Marantz keep saying that hate speech lead to tangible harmful violence. Unfortunately, he never explain clearly how noxious online speech can cause a real violence. Like the case of El paso. Noxious online language is not the main the reasons why this case happens. Based on the data from washington.com the motive of the shooting in EL Paso is because of the movement againts immigrants. So, we should actually know that basically noxious language is not really lead people to do violence because there might be others biggest reasons why cases of El Paso and Charlottesville happens.

Based on the excerpt above the analysis written by the student still referred to the summary style by rephrasing or rewriting the author's opinion on the article [5]. As a part of the analysis, the response could question the author's purpose to use Narendra, Modi, 
Rodrigo, Donald Trump, or the El Paso as the examples of noxious speech. However, the evaluation turned into the reason for El Paso incident without giving further examination. As the result, the student failed to refute or disagree to the author's opinion from the analysis and evaluation.

The summary style written by the student indicated that she did not question the author's purpose on writing the article and just retrieved the information from the article as a save reader. A save reader is a part of noncritical readers where the reader only remembering or memorizing the information and restating the main points without highlighting the author's purpose [5]. The summary level is the basic level of critical reading in which there is no interference from the readers to validate the information. Therefore, when a student still uses the summary style to analyse the text, the repetitive action will be memorizing and restating.

Another excerpt shows how another student could successfully criticize the same article by comprehending the levels of critical reading.

\section{Excerpt 2 (Student B)}

Descriptive: Marantz no longer has any doubt about the dangers of speech, and he shows how dangerous it is from a view of how the massacres in New Zealand is triggered by how the media spreading the islamophobia.... He also start to give some examples on how speech could turn human possibility in having a roles; Donald Trump, Narendra Modi, and Rodrigo Duterte are the examples of peoples who can maximize the use of speaking...

Interpretation: By writing "Free Speech is Killing Us", Marantz should be implied as a supporter of the Regulation that limiting the Freedom of Speech, but his uncertainty comes after his question that asking what should we do about the Freedom of Speech, and he answer no.... The uncertainty of the author can also be seen at how he criticizes the 1st amendment as the reason for the backfire of the government, but then also saying that he not calling to repealing the 1 st amendment.

Evaluation: The author's bias about how the speech could "leap into the world of flesh and blood" is also not entirely correct, data from the FBI at a Pew Research Center website shows that in the past 30 years, the amount of violence is continuously decreasing.... Marantz has a weakness in correlating each of his points, he need to be careful when jumping from one point to another points; If Marantz cannot explains the correlation of his points that eventually in this article is contrary, it would shows the author uncertainty; in some moments Marantz clearly contradict to some point, but then he giving an argument that contradicting his contradiction.

The data shows how the student had identified and analysed the author's point of view how he might be the supporter of the noxious speech victims by giving several evidence taken from the article. However, he also found an ambiguity in which the author may have a dual side for the uncertainty. Thus, the student criticized how the author's argument could be invalid from the evidence used and the way argument written from the transitions between one argument to another argument as one of the components in rhetorical analysis [17].

The evaluation written by Student B also shows how he reviewed the bias position by looking at the structure and the language to support the author's purpose. The organization structure enables the readers to identify the elements and the relationship to analyse the author's purpose [18]. The main purpose of reviewing the text is to evaluate how the author has successfully achieved his or her purpose [5]. Thus, Student B reached to a conclusion how the author failed to confirm his purpose to support or oppose the free speech.

\subsection{Students' Ability to Apply Toulmin Reasoning Element}

The reasoning elements start from the description level in which students provided their claim by identifying the structure or some aspects in the article. Therefore, the number of samples was reduced into eleven essays since the other samples did not provide the claim on the text identification. The elements were categorized based on the reading level as an indicator the number of students successfully applying each element to the next reading level. In other words, the Toulmin Model is used as a part of critical reading level to assess students' analytical skill. Based on the data, 11 students had been able to implement the claim element to identify the author's purpose or point of view. Only one student who had difficulties to give data on the author's position or purpose. However, not all students could give strong backing to support the author's argument by having zero number from table 2 below. At the same time, only $18,75 \%$ students who could successfully counter the author's argument from their evaluation. Moreover, the table shows the decreasing number significantly from the element of warrant.

Table 2 Toulmin reasoning element integrated with Reading Level

\begin{tabular}{|l|l|l|}
\hline Reading Level & $\begin{array}{l}\text { Toulmin } \\
\text { Elements }\end{array}$ & $\begin{array}{l}\text { Number of students } \\
\text { (out of 16) }\end{array}$ \\
\hline Summary & - & 16 \\
\hline \multirow{2}{*}{ Descriptive } & Claim & 11 \\
\cline { 2 - 3 } & Data & 10 \\
\hline Interpretation & Warrant & 7 \\
\hline \multirow{2}{*}{ Evaluation } & Backing & 0 \\
\cline { 2 - 3 } & Rebuttal & 3 \\
\hline
\end{tabular}


The ability of students fails to interpret a warrant could be due to the difficulties to understand interpreting the meaning of the connotative words or sentences in the text. In critical reading, some sentences could have denotative and connotative meaning, and some readers just focus on the denotative meaning to do the interpretation [19]. Therefore, they cannot find the implicit message behind the text or even create a logical analysis to explain the argument made. The sample response below shows how a student failed to analyse the claim she wrote as a response to "Why is Your Women's Event Missing Women of color?" written by Janice Gassam Asare.

\section{Excerpt 3 (Student C)}

Claim: Janice Gassam uses psychological sides to build her argument.

Evidence: She clearly states that in the recruitment process of panelists and speakers for women's events, there is often a bias factor in who is seen as a field expert.

Warrant: It seems logical to interpret a bias as a reason for not having diversity on the list of speakers.

The student identified the approach of the author to write the argument by stating "the psychological side" and gave the specific argument for her claim. However, she did not elaborate the psychological sides used by the author and did not examine the concept of bias in the article. Thus, the inability to infer those two ideas or words, psychological sides and bias, is a hinder to explain the logical analysis between the claim and data made by the student.

The number of backing and rebuttal may also indicate that some students had difficulties to respond to the author's argument either by giving more backing or rebuttal. The excerpt below indicated how student D could apply warrant by looking at the implied message from the author yet failed to give the backing as a response to "Why is Your Women's Event Missing Women of color?" written by Janice Gassam Asare.

\section{Excerpt 4 (Student D)}

Claim: In this article, Gassam's parallel concern is the question of women's pay parity.

Data: Luvvie Ajayi, who is a woman of color, experienced this issue of pay parity in 2017 when she was asked to speak at a large conference that refused to pay for her. Meanwhile, the organizer pays for the white women speakers.
Warrant: By using this evidence, gassam convince that in practice, unfortunately, the organizer is not always engaging what they aim to be. She emphasizes that if the organizer is actually concerned about the women's event, the organizer should pay women equally.

Backing: Gassam would point out, correctly, that pay parity issue, especially among women, is still existing. It is shown on the Institute for Women's Policy Research (IWPR), In 2018, full-time, year-round female workers made a gender wage gap of 18 percent for only 82 cents per dollar received by men. IWPR also predicts that when reform occurs at the same slow pace as it has done over the past 50 years, it will take 40 years - or 2059 - for women to finally reach pay parity.

The excerpt shows student D already inferred the author's message or intention by looking at the evidence used. However, her backing did not reveal more on the issues of multicultural events although she stated the evidence of gender difference on the pay system in her backing. Her backing gave data on the unequal salary between women and man, but the context of her evaluation was more on the ethnicity background which is not only referring to gender or sexes. Her backing shows how she did not focus on the subject matter of the primary text. As suggested by Suzanne, that active reading needs reflecting skill to read the text by focusing on the subject matter [5]. However, the reflective skill done by the student does not indicate the focus of the backing which is the diversity issue.

Another problem on the subject matter also appears in one of the critiques to refute the author's argument. One of the responses to "The Spirit of Eugenics is still with Us, as Immigrants Know to Their Cost" by Kenan Malik reveals how Student E did not focus on the point of evaluation by giving less evidence to debate.

\section{Excerpt 5 (Student E)}

Claim: In this article the author is a pro-Eugenic enthusiast or perhaps a supporter of Eugenics in our advanced modern society.

Data: He listed every possible solutions to major issue of Eugenics that are happening in our planet such as poverty, overpopulation, and illegal immigration.

Warrant: This view of immigrants are perspective of right-wing nationalist who are possibly Eugenicists, that claims immigrants should be discouraged and limited by their government because they are viewed as invaders or criminals in minds of a conservative.

Rebuttal: I don't support the idea of Eugenics in our society or in general its impact towards the lower order. It's an attack on democracy of the world or perhaps a corruption of democracy because the lower order of our 
society doesn't have a voice to represent their decisions or opinions.... This article 1 from the UNCHR is an illustration that the enlightened and the lower order of our society are presented equal in terms of their rights. It means everyone is equal no matter how different they are regardless of who they are and where they came from.

Excerpt 5 shows how student E could identify the author's position as a supporter of Eugenics from the author's argument and evidence. He tried to make a logical thought how this concept was the purpose of right-wing nationalist to stabilize the country by eliminating the inferior groups. However, when he stated his position to disagree with the author, the evidence was not strong enough to explain why that solution or concept was not applicable in the modern society or democracy only by referring to the article 1 taken from UNHCR. The evidence he took did not argue the main point how Eugenics could not be the solution for population and democracy. Therefore, he failed to evaluate the author's point of view on Eugenics. As stated by Rex et al., some qualities of evidence are credible, sufficient, and accurate [20]. The article from UNHCR may be credible, but it is not sufficient or accurate enough to deny the idea of Eugenics as the answer of global issues.

On the other hand, another response from the student F chose to evaluate the concept of Eugenics in todays' society by looking at the specific issue to analyze as shown in excerpt 6 .

\section{Excerpt 6 (Student F)}

Claim: Malik sees the genetic development and the appearance of "designer babies" as a frightening desire to create individuals with superior genetics.

Data: Malik strengthens his argument by Angela Saini and Adam Pearson's documentary film "Eugenics: Science's Greatest Scandal”.

Warrant: If Galton's idea is realized, there will be a potency for inequality and discrimination happens from superior racial groups towards disability groups or poor people.

Rebuttal: the first genome-edited baby that was claimed to be breaking the law and is feared will evoke the spirit of eugenics, turned out to have a noble aim to prevent the baby from getting HIV infection passed down from his parents (Cyranoski and Ledford 607- 608). Again, Malik cannot generalize that genetic modification nowadays is associated with the eugenics principle. There are many reasons behind genetic modification, and not all of them are related to eugenics.
Result of student $\mathrm{F}$ excerpt shows how the rebuttal was used to counter the concept of Eugenic as the real motive of the rapid technology in the modern society. She provided data to weaken the author's evidence related to the creation of prominent gen. Furthermore, she highlighted that the author's data on genetic modification could not be seen as the general idea for the whole purpose of modern science. Therefore, she applied hasty generalization as one of the logical fallacies to evaluate the author's flaw on the argument and data presented [17]. In addition, she focused her rebuttal on the specific issue to object which is about the reason for genetic development. In other words, the way she evaluated the text was breaking down the text into several parts as the readers read and identify the ideas [21].

\section{CONCLUSION}

Based on the data and analysis, it is revealed that the students' ability to read critically is still less than $50 \%$ by looking at the interpretation and evaluation level. In addition, only $18.8 \%$ of students could successfully criticize the articles. Their ability to use reasoning elements also indicated that they still need more background knowledge to identify and interpret the text overall. The data also gave an overview that most of them were still on the level of summary and descriptive by applying the claim and data to identify the text. It also shows that the writing ability to create logical analysis is still under those two elements which are claim and data, and few students already possessed the ability to perform warrant for inference.

Therefore, some recommended actions are needed to increase this analytical skill to interpret and evaluate text. One of them can be an intensive reading program in which the students will be exposure to various kinds of text and get background knowledge to evaluate text using the prior knowledge or schemata. The process of pre-reading, while reading, and post-reading activities helps readers to read comprehensively by using the prior information [22]. Therefore, the doing re-reading with several emphasizes is important to know the content and textual structure. However, that reading process should be accommodated with several skills which are annotating several important points, reviewing the information to evaluate the author's purpose, and comparison of several works to see the author's bias and objectivity [5]. In other words, those activities should be a part of pre-assessments to write a critique or response essay. Therefore, the ability of read and write critically can be improved.

\section{ACKNOWLEDGMENTS}

Financial support of this research was given by Sampoerna University as a part of professional development. The researcher would also express the 
sincere gratitude for the colleagues who gave the suggestions in writing the manuscript.

\section{REFERENCES}

[1] L. M. Murawski. Critical Thinking in the Classroom Beyond. Journal of Learning in Higher Education, 10(1), 2014, pp. 25-30.

[2] H. Nold. Using Critical Thinking Teaching Methods to Increase Student Success: An Action Research Project. International Journal of Teaching and Learning in Higher Education, 15 (1), 2017, pp. 17-32. http://www.isetl.org/ijtlhe

[3] T. Lestari, D. A. L. Bharati, \&D. Rukmini. Developing Project-Based Writing Assessment Module to Stimulate Students' Critical Thinking and Creativity. English Education Journal, 8(4), 2018, pp. 499-507. DOI 10.15294/EEJ.V8I4.25809

[4] K. J. Lunsford. Contextualizing Toulmin's Model in the Writing Classroom: A Case Study. Written Communication, 19(1), 2002, pp.109-174. https://doi.org/10.1177/074108830201900105

[5] N. Suzanne. Being Active Readers by Applying Critical Reading Technique. Ta'dib, 14(1), 2011, pp. 52-64. http://dx.doi.org/10.31958/jt.v14i1.197.

[6] R. A. Bermani, Safnil, \& Arono. An Analysis Argumentative Structure of Research Article of English Postgraduate Program of Bengkulu University Published in Journal. Journal of Applied Linguistics and Literature, 2(2), 2017. https://doi.org/10.33369/joall.v2i2.5954

[7] A. B. Resakti, Safnil, \&Arono. An Analysis of Argument Structure of Research Article of English Post. Journal of Applied Linguistics and Literature, 2 (2), 2017, pp. 47-64.

[8] P. A. Leong. Thinking Critically: A Look at Students' Critiques of a Research Article. Higher Education Research \& Development, 32(4), 2013, pp. $575-589$. http://dx.doi.org/10.1080/07294360.2012.708322

[9] M. Tengberg \& C.O. Scheller. Developing Critical Reading of Argumentative Text: Effects of a Comprehension Strategy Intervention. Journal of Language Teaching and Research, 4(7), 2016, pp. 635-645.

DOI: http://dx.doi.org/10.17507/jltr.0704.02

[10] J. VanDerHeide, M. Juzwik, \&M. Dunn. Teaching and Learning Argumentation in English: A Dialogic Approach.. Theory Into Practice, 55 (4), 2016, pp. 287-293. DOI: $10.1080 / 00405841.2016 .1208069$
[11] J. B. Freeman. Argumentative Structure Representation and Theory. Springer, 2011.

[12] M. Simosi. Using Toulmin's Framework for the Analysis of Everyday Argumentation: Some Methodological Considerations. Argumentation, 17(185), 2003.

https://doi.org/10.1023/A:1024059024337

[13] J. Qin, \&E. Karabacak. The Analysis of Toulmin Elements in Chinese EFL University Argumentative Writing. System, 38, 2010, pp. 444456. doi:10.1016/j.system.2010.06.012

[14] B. Oliveras, M. Marquez, \&N. Sanmarti. The Use of Newspaper Articles as a Tool to Develop Critical Thinking in Science Class. International Journal of Science Education, 35(6), 2013, pp. 885-905. doi: 10.1080/09500693.2011.586736

[15] S. Elo, M. Kaariainen, O. Kanste, T. Polkki, K. Utriainen, \& H. Kyngas. Qualitative Content Analysis: The Focus of Trustworthiness. SAGE Open, January-March, 2014, pp. $1-10$. DOI: $10.1177 / 2158244014522633$.

[16] M. Bengttson. How to Plan and Perform a Qualitative Study Using Content Analysis. Nursing Plus Open, 2, 2016, pp. 8-14.

https://doi.org/10.1016/j.npls.2016.01.001

[17] A.A. Lunford, J.J. Ruszkiewicz, K. Walters Everythings' an Argument with Readings. Bedord/St. Martin's, 2016.

[18] C. Bazerman. The Informed Writer: Using Sources in the Disciplines. The WAC Clearinghouse, 2010.

[19] F.G. Jayanti. Reading Difficulties: Comparison on Students' and Teachers' Perception. Proceedings of the Fourth International Seminar on English Language and Teaching, 4(1), 2016, pp. 296-301. http://ejournal.unp.ac.id/index.php/selt/article/view 16939

[20] L.A. Rex, E.E. Thomas, \& S. Engel. Applying Toulmin: Teaching Logical Reasoning and Argumentative Writing. English Journal 99(6), 2010, pp. 55-61.

[21] H. Kucukoglu. Suggestion to Improve Critical Reading Applications in ELT/EFL Classes. In FLTLAL 2011 Proceedings/1st International Conference on Foreign Language Teaching and Applied Linguistics May 5-7, 2011, pp. 620-629.

[22] H. Akyol, A. Çakıroğlu, \& H. Kuruyer. A Study on the Development of Reading Skills of the Students Having Difficulty in Reading: Enrichment Reading Program. International Electronic Journal Of Elementary Education, 6(2), 2017, pp. 199-212. 